\title{
Courtyard integrated ecological system: An ecological engineering practice in China and its economic-environmental benefit
}

\author{
Baolong Han ${ }^{l}$, Zhiyun Ouyang $*^{l}$, Hongxiao Liu ${ }^{l}$, Zhifu Cui ${ }^{2}$, Zhongming $L u^{3}$ \\ ${ }^{l}$ Research Center for Eco-Environmental sciences, Chinese Academy of Sciences, China; \\ ${ }^{2}$ Hainan Agricultural Reclamation Academy of Sciences, China; \\ ${ }^{3}$ Georgia Institute of Technology, USA
}

\begin{abstract}
:
Rural residential areas and low resident density areas are usually distressed by the lack of municipal infrastructure, which causes a poor supply of water and energy, as well as a shortage of the waste and pollution disposal equipment The courtyard integrated ecological system (CIES) is an example of an ecological engineering solution to this problem. CIES originated in the Hainan rural area of China. This family level symbiotic system was designed by the authors according to a few sustainable principles, such as making good use of local natural resources, low cost, convenience of operation, and resource recycling. CIES systematically integrated a series of single techniques, such as vertical planting, hydroponic farming, artificial wetland, rainwater harvesting and automatic management, and so on. After a brief introduction of the CIES design, this article also studied its economic-environmental benefit with one year of monitoring data and a comparison between the CIES pattern and traditional pattern with both emergy analysis and carbon footprint analysis methods. The results showed that CIES could provide an increase of 75 $\mathrm{m}^{2}$ of green land, $40 \mathrm{~m}^{3}$ of green volume and $2400 \mathrm{~kg}$ of vegetables for each rural family. In addition, each family could save $277 \mathrm{kWh}$ of electric power, $70.87 \mathrm{t}$ of fresh water, $7.5 \mathrm{~kg}$ of chemical fertilizer and $450 \mathrm{~g}$ of pesticides each year. Additionally, counting the money saved, each CIES can produce more than 38,000 RMB after 1.28 years of payback. Compared to the traditional living pattern in a local area, the CIES pattern costs only $19.4 \%$ of the former's emergy and $49.6 \%$ of the carbon footprint of the traditional living pattern. Assuming that CIES is applied to half of the rural households in Hainan Province, each farmer would receive an extra 2842 RMB for each year, the emergy consumed by the system would be reduced by $1.6 * 10^{21}$ sej, and $\mathrm{CO}_{2}$ emissions would be reduced by $1.036 * 10^{5} \mathrm{t}$.
\end{abstract}

Keywords: Courtyard integrated ecological system; Economic-environmental benefit; Carbon emission; Emergy; Rural area

\section{Introduction}

Researchers usually pay a great deal of attention to the high speed of Chinese urbanization and its accompanying environmental problems. Those problems, such as lack of fresh water and poor air quality, are mainly caused by urban areas that usually have a high population density (Xie et al. 2013, Wei et al. 2015, Zhou et al. 2016). However, compared to urban areas, we should not be too optimistic about the environment in rural areas. Although the rural area has a larger environmental capacity due to its vast territory and sparse population, the residential environment in a rural village presents a dirty and disordered situation due to the lack of municipal infrastructure and low awareness of environmental protection on the part of the residents (Yu 2014, 
Zhang et al. 2016). China is a large agricultural country, and there is a population of 8000 million people living in rural areas. Only $19.4 \%$ of the villages have centralized sewage treatment, and $24.5 \%$ of the villages have central drinking water treatment. Only $36.7 \%$ of the villages have garbage treatment stations, and $15.8 \%$ of the villages have central disposal of household garbage (Li et al. 2010, Jiang et al. 2011, Zhou 2012, Yu 2014, Li et al. 2015). Recently, problems have become even worse because of the rising tendency of suburban tourism.

Environmental protection endeavors in rural areas mainly focus on the disposal of sewage and waste from residential living and agricultural activities. With the aim of reducing sewage disposal, technologies, engineering measurements and their integration have been extensively studied and significant progress has been made (Liu et al. 2014, Ma and He 2014a) . Research has been conducted in China regarding scattered sewage water disposal technologies since the 1980s. Current technology can be summarized into two categories according to its processes and principles. One disposal technology is the "simplified and miniature urban sewage treatment plant" treatment scheme, which is similar to sewage treatment plants in urban areas ( $\mathrm{Lu} \mathrm{2001,}$ Chen and Zhang 2013, Liu et al. 2014, Ma and He 2014b) The water treatment carriers are mainly activated sludge and biofilms, for example, high load anaerobic treatment technology, with a biological aerated filter. The other disposal technology is a "natural treatment system", similar to a traditional oxidation pond or soil filtering technology, which disposes sewage through soil filtering, with plants absorbing and microbes decomposing sewage. The carriers in such technologies are soil infiltration and a stabilization pond. In addition, there are some practices, such as earthworm ecological filtration, contact oxidation, artificial wetland technology, among others, that combine the two types of technology (Lu 2001, Liu et al. 2014, Ma and He 2014b, Lam et al. 2015)

In terms of waste disposal, China has accumulated a great deal of experience in traditional intensive cultivated agricultural activities (Gao et al. 2015, Yu et al. 2015) . Based on the systemic principle and the integrity principle, China has developed courtyard agriculture systems, mulberry fish ponds, composting techniques, interplanting and intercropping techniques, among others, which provide helpful references for solving waste disposal problems today. The courtyard agriculture system refers to the practice of farmers making use of the space and resources in the courtyard to conduct planting, breeding, and manufacturing in their yards to make use of waste resources and increase their income ( $\mathrm{Lu} 2001, \mathrm{Wu}$ et al. 2015). A traditional courtyard ecological engineering system is integrated with "biogas" as a material transformation center that unites farming, aquaculture, manufacturing, and rural energy into one system. The excrement of people and livestock provides raw material to generate biogas, and the biogas residues are reused as fertilizer for fruits, vegetables, flowers, fish, and so on. Basically, there are several types of courtyard ecological agriculture systems: beautification and greening courtyard agriculture, fruit-vegetable intercropping ecological agriculture, profit oriented courtyard agriculture, facility feeding ecological agriculture, "planting-feeding-biogas-toilet" ecological agriculture, and "planting-mushrooms-feeding-biogas-fertilizer" courtyard ecological agriculture(Liang et al. 1998). Researches indicated that the economic benefit of the courtyard system can range from 1.74 thousand RMB to 16 thousand RMB per year. However, this traditional agricultural recycling technology is based on the reuse of human and animal excreta and improves the income of the farmer. The system did not consider the broad integration of current technological progress, and 
thus, the overall environmental performance is not ideal.

Considering the above mentioned approaches to resolve rural environmental issues, there are some obvious problems: Rural sewage treatment and solid waste recycling are mutually independent and are not integrated into a system. The centralized disposal approach has stable requirements regarding human and animal excreta as well as sewage that are difficult to meet in remote and scattered rural areas. Although the traditional courtyard agriculture system, which is based on systematization and integrity, has relatively high economic benefits, the overall environmental performance is not satisfactory and the traditional courtyard agriculture system requires excessive labor input, which is not suitable for the labor shortage situation in some rural areas. In addition, the above mentioned method is based on a single environmental goal and a single technology, overlooking other environmental goals, such as rain water and solar energy reuse. Systematic design and integration of different ecological technologies and engineering are needed to achieve multiple sustainable development goals. Based on these considerations, this research designed an integrated courtyard ecosystem to demonstrate the effectiveness and feasibility of integrating multiple ecological technologies and engineering methods according to the situation in the case study area. The project integrates hydroponic cultivation, rainwater reuse, sewage disposal recycling, three-dimensional greening, solar power generation, and family compost technology into one courtyard ecosystem. At the same time, the system achieves automation by adding intelligent management devices to save human labor. We conducted emergy footprint, carbon emission and cost-effectiveness analysis to evaluate the environmental and economic performance of the system based on one year of monitoring data to investigate the environmental performance of the system.

\section{Data and method}

2.1 Courtyard integrated ecological system

We chose the house of a common farmer in Baoting County, Hainan Province, China, as our study area. The temperature and climate are suitable for a system with abundant plants and other organisms. The house is a one-story flattop brick house with a $100 \mathrm{~m}^{2}$ ground area and is $3.5 \mathrm{~m}$ in height. The land around this house is a pervious area. Ordinarily, one young couple (male, 29 years of age; female, 26 years of age), their daughters (6 and 7 years of age) and their parents (male, 51years of age; female, 52 years of age) live in this house. As a common farming family in Hainan, they usually use $500 \mathrm{~L}$ of fresh water and $1 \mathrm{kWh}$ of electrical power per day from May to November. They utilize $300 \mathrm{~L}$ of fresh water and $0.5 \mathrm{kWh}$ of power in the other seasons when the temperature is lower. The basic situation is shown in Fig. 1.

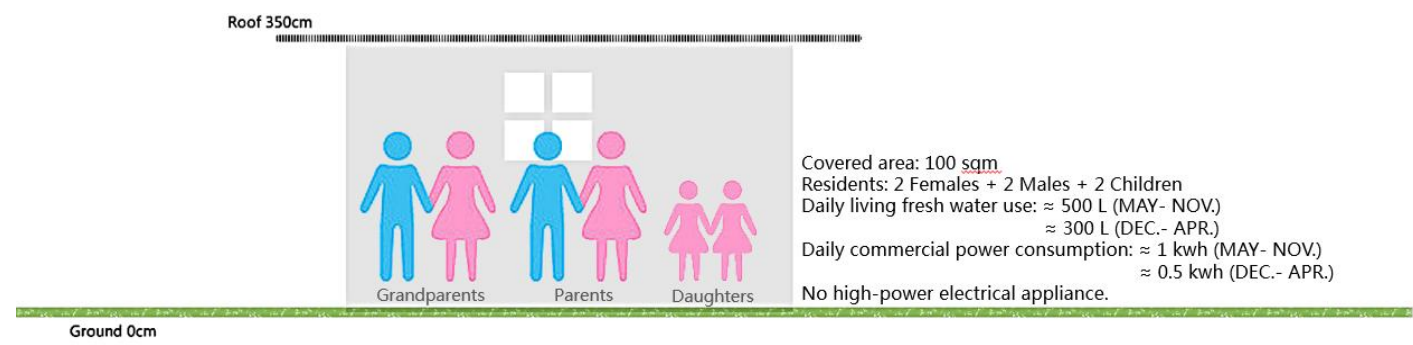

Fig. 1. Original situation of study house.

The case study area is rich in rainfall capacity (average $1267 \mathrm{~mm} / \mathrm{a}$, and more than $90 \%$ of the rainfall occurs from May to November) and solar radiation (total 140 kilocalorie $/ \mathrm{cm}^{2} / \mathrm{a}$, more than 2500 sunshine duration hours/a). The authors performed a field investigation and distributed 
questionnaires to local people regarding their residential environment. There is no municipal infrastructure in rural areas, especially those areas far from cities. Energy supplements are usually unstable. Waste, such as human excreta, wash sewage and kitchen waste, are not treated but allowed to outflow around the house and pollute the land. To address the local environmental problem, the authors suggested the use of a few technologies, including photovoltaic power, rooftop planting, three-box septic tanks, artificial wetlands and composting fermentation, among others. Fig. 2 (left) shows the featured issues that occurred in the study area and their potential solutions.

However, a simple combination of different technologies might cause more problems because there are other types of wastes left after dealing with the original waste. For a comprehensive solution, the authors designed a Courtyard Integrated Ecological System (CIES) as an ecological recycling system for the study area. Fig. 2 (right) shows the concept design and the technological route to a CIES. When the technologies were applied to this house, the engineering installation sketch map resembles that shown in Fig. 3. CIES has 8 main parts. 1) Rainfall was collected from the roof for as a water supplement for the fish tank and the toilet flush water. 2) Urine from the indoor urine-feces separation eco-toilet stood separately for 2 months and was then used as a fertilizer for the farmland. 3) Feces and the toilet flushing water flowed into the 3-box septic tank for sedimentation. Then, the overflow waste water from the septic tank flowed into the artificial wetland. 4) The overflow water from the fish tank flowed into the artificial wetland as well. After decontamination of the wetland, water was pumped for irrigation for roof hydroponic farming and wall greening. 5) A back light lamp was used to kill pests, instead of pesticides. 6) Other organic kitchen and farm wastes were collected for the composting bin for organic fertilizer production. 7) A smart central control system (Fig. 4), with a weather station, data recording, and remote control functions, was used to manage the whole CIES. The hardest part was adjusting the proportion among the different nutrient materials in the recycling water for better hydroponic farming. This problem was solved by an arithmetic calculation for timing the pump operation that was set in the smart control system. 8) A solar power system supplied all of the required electricity of the CIES, such as the pump, lamp, courtyard weather station, fish tank filter, and so on.

Fig. 5 shows a picture of the CIES in Baoting after one year of stable operation. The key issue in this article is to discuss the economic-environmental benefit of the CIES, not its design. For patent protection reasons, we cannot present further details of the components of the CIES. However, some defects will be discussed in the Discussion section.
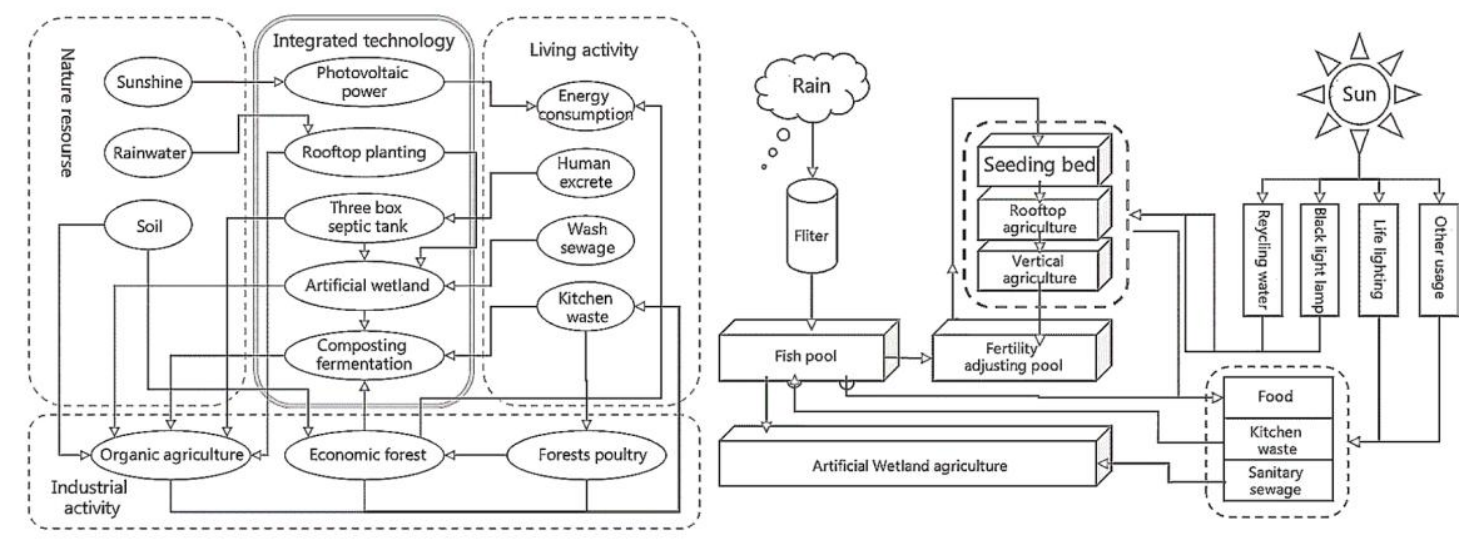

Fig. 2. Design concept for the CIES 


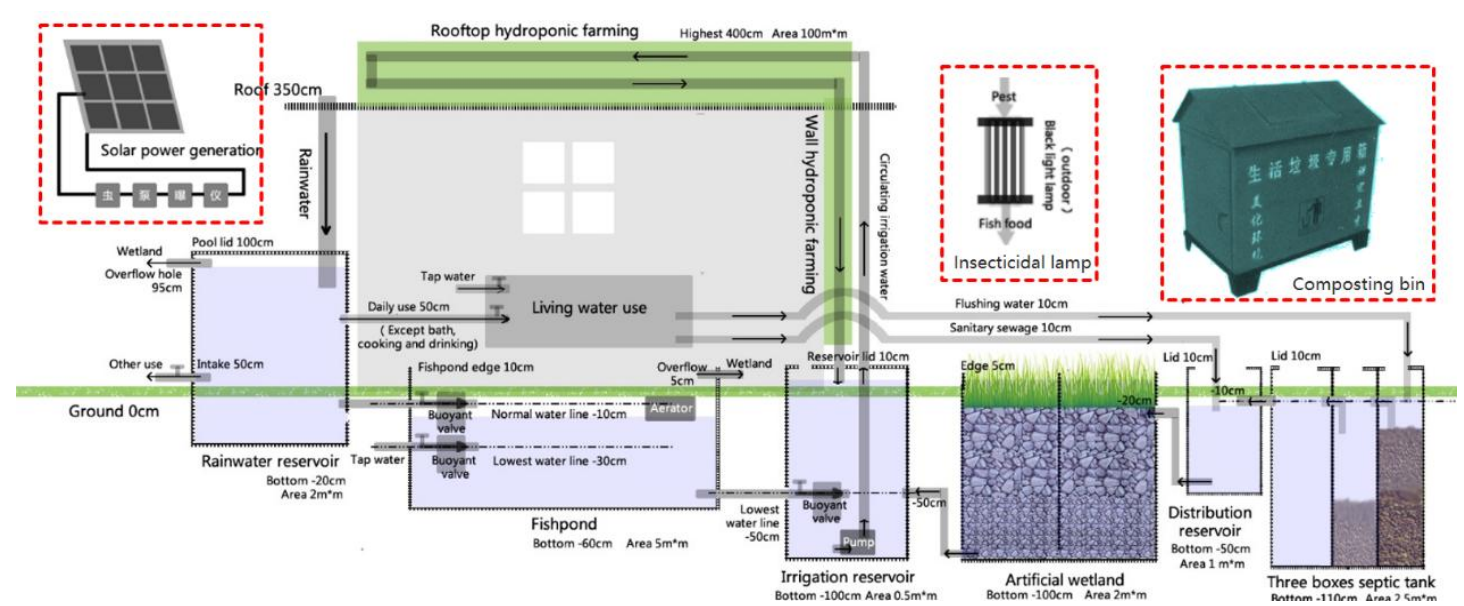

Fig. 3. Engineering structure design for the CIES
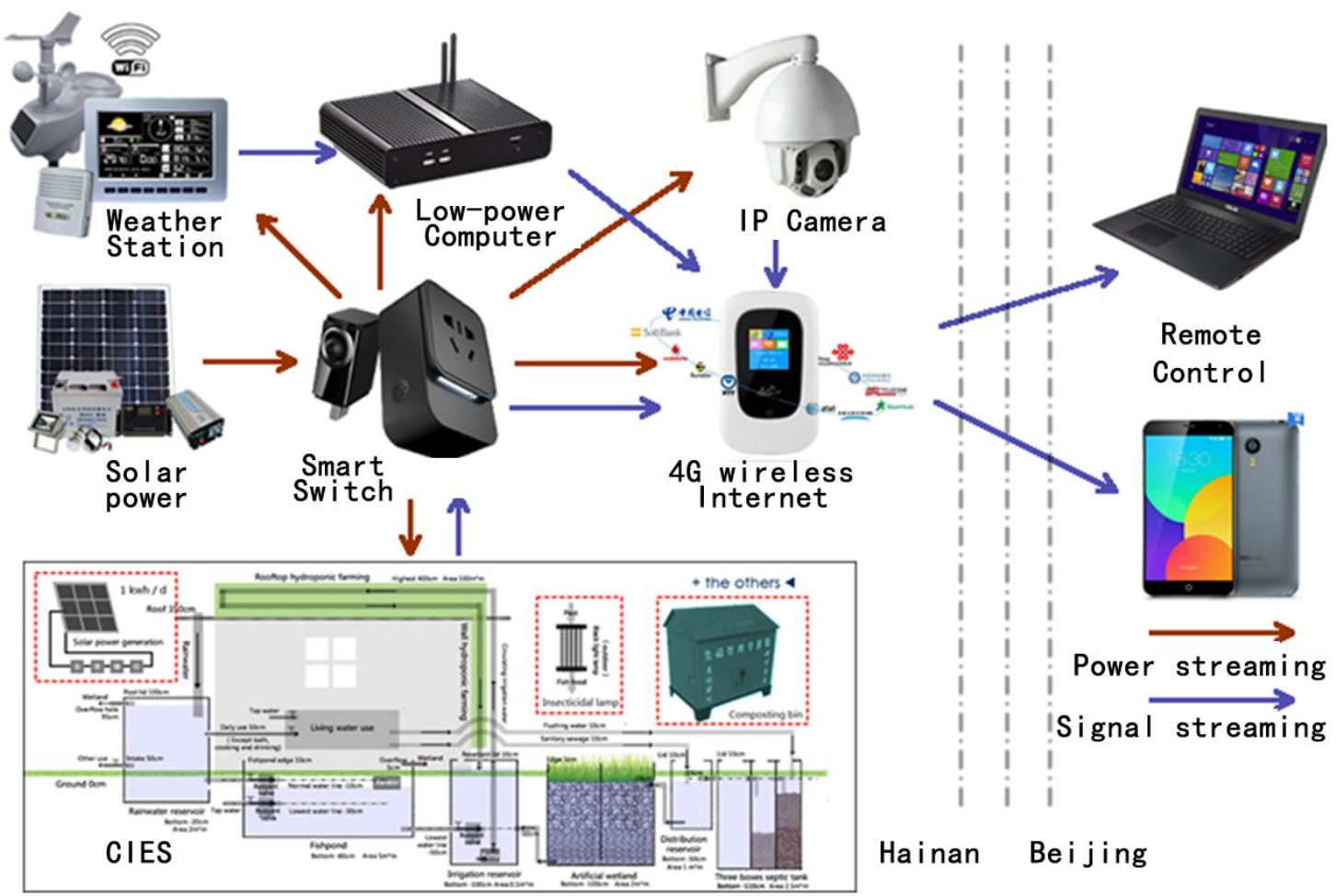

Hainan Beijing

Fig. 4. The smart remote management system for the CIES

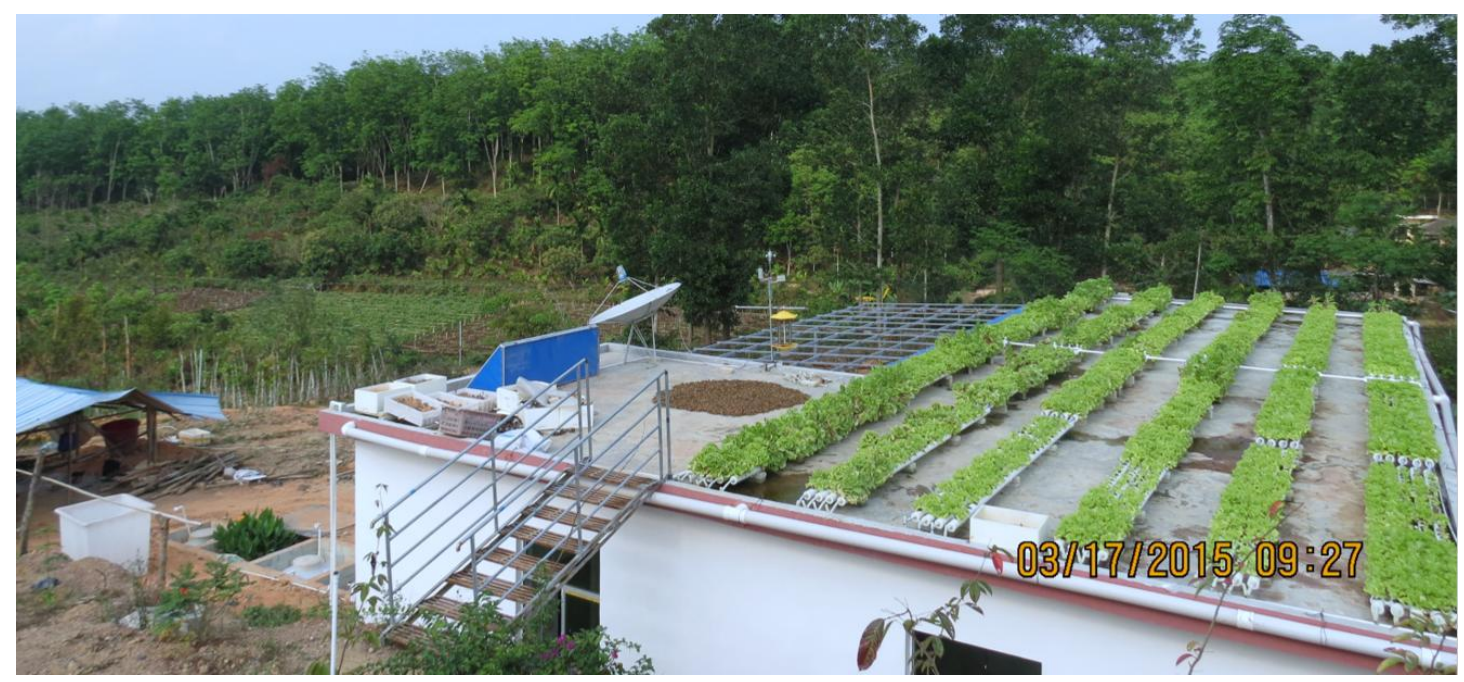


Fig. 5. Actual scene for the CIES in Hainan

\subsection{Data resources}

The data used for the CIES in this article were collected from a one-year monitoring record and the construction record. The data used for the comparison with the traditional pattern were from statistical yearbooks, such as Hainan yearbooks and Chinese water resource yearbooks. Those data included the price of vegetables, payment for the labor force, price of electricity, demand for irrigation water, and so on. When there were no specific data for Baoting, we used the average value for Hainan Province. When we considered the weight of the construction materials used in CIES, we dismissed the light portion of the construction materials, the weight of which was less than $1 \%$ of the total weight. This mode of determining resources complies with Life Cycle Assessment (LCA) standards.

\subsection{Method}

Emergy is a type of energy that is consumed in direct and indirect transformations that are needed to produce a product or service (Odum and Peterson 1996). Emergy is a measure of the differences in quality between different forms of energy and an expression of all of the energy that is used in work processes that generate a product or service in units of one type of energy. Emergy is measured in units of sej, a unit referring to the available energy consumed in transformations. Emergy accounts for different forms of energy and resources (e.g., sunlight, water, fossil fuels, minerals, etc.). Each form is generated by transformation processes in nature, and each has a different ability to support work in natural and human systems. The recognition of these quality differences is a key concept (Odum and Peterson 1996).

The concept name of the carbon footprint originates from the ecological footprint. A carbon footprint is defined as "a measure of the total amount of carbon dioxide $\left(\mathrm{CO}_{2}\right)$ and methane $\left(\mathrm{CH}_{4}\right)$ emissions of a defined population, system or activity, considering all relevant sources, sinks and storage within the spatial and temporal boundary of the population, system or activity of interest. Calculated as carbon dioxide equivalent $\left(\mathrm{CO}_{2} \mathrm{e}\right)$ using the relevant 100-year global warming potential (GWP100)." (Alvarez et al. 2016, Holland et al. 2016). In 2007, the carbon footprint was used as a measure of carbon emissions to develop the energy plan for the city of Lynnwood, Washington. Carbon footprints are more specific than ecological footprints because they measure direct emissions of gases that cause climate change into the atmosphere.

\section{Results}

3.1 Main data from one year of monitoring

The following tables present data from the construction of the CIES and its one year of stable operation. Table 1 and Table 2 describe the water balance and power balance in the CIES. The materials used in the construction of the CIES are shown in Table 3. Water quality was used to determine the operational status of the CIES; the results of testing the water quality are shown in Table 4. In addition, the authors recorded the time consumption for one year of operation of the CIES and performed a comparison with the traditional pattern in Table 5.

Table 1. Daily water demand-supply balance

\begin{tabular}{ccccc}
\hline & \multicolumn{2}{c}{$\begin{array}{c}\text { May-Nov. } \\
\text { (Daily Average ) }\end{array}$} & \multicolumn{2}{c}{$\begin{array}{c}\text { Dec.-Next April } \\
\text { (Daily Average) }\end{array}$} \\
\cline { 2 - 5 } Procedure & Supply & Demand & Supply & Demand \\
\hline Rainfall & $600 \mathrm{~L}$ & - & $200 \mathrm{~L}$ & - \\
Wash water recycling & $450 \mathrm{~L}$ & - & $270 \mathrm{~L}$ & - \\
\hline
\end{tabular}




\begin{tabular}{|c|c|c|c|c|}
\hline Urination flush water recycling & $5 \mathrm{~L}$ & - & $5 \mathrm{~L}$ & - \\
\hline $\begin{array}{c}\text { Wetland planting } \\
\text { ( include evaporation ) }\end{array}$ & - & $100 \mathrm{~L}$ & - & $150 \mathrm{~L}$ \\
\hline $\begin{array}{c}\text { Living use } \\
\text { ( include leakage ) }\end{array}$ & - & $200 \mathrm{~L}$ & - & $100 \mathrm{~L}$ \\
\hline Fish tank evaporation & - & $20 \mathrm{~L}$ & - & $40 \mathrm{~L}$ \\
\hline Wall planting & - & $40 \mathrm{~L}$ & - & $60 \mathrm{~L}$ \\
\hline $\begin{array}{l}\text { Hydroponic vegetables } \\
\text { (include evaporation) }\end{array}$ & $\bar{\square}$ & $450 \mathrm{~L}$ & - & $250 \mathrm{~L}$ \\
\hline Water pipe leakage & - & $55 \mathrm{~L}$ & - & $55 \mathrm{~L}$ \\
\hline $\begin{array}{c}\text { Balance } \\
\text { ( From underground water ) }\end{array}$ & $-190 \mathrm{~L}$ & 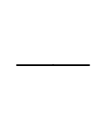 & $180 \mathrm{~L}$ & - \\
\hline
\end{tabular}

Table 2. Daily power demand-supply balance

\begin{tabular}{ccccc}
\hline Electrical Loads & Power & Daily Work Hours & $\begin{array}{c}\text { Daily } \\
\text { Electricity } \\
\text { Consumption }\end{array}$ & $\begin{array}{c}\text { Daily } \\
\text { Electricity } \\
\text { Production }\end{array}$ \\
\hline Solar power generation & $300 \mathrm{~W}$ & 8 hours & - & $2 \mathrm{KWH}$ \\
Hydroponic pump & $400 \mathrm{~W}$ & 0.5 hour & $0.2 \mathrm{kWh}$ & - \\
Wetland oxygen pump & $20 \mathrm{~W}$ & 1 hour & $0.02 \mathrm{kWh}$ & - \\
Fish filter pump & $40 \mathrm{~W}$ & 3 hours & $0.12 \mathrm{kWh}$ & - \\
Fish oxygen pump & $30 \mathrm{~W}$ & 3 hours & $0.09 \mathrm{kWh}$ & - \\
Black light lamp & $20 \mathrm{~W}$ & 8 hours & $0.16 \mathrm{kWh}$ & - \\
Control computer & $20 \mathrm{~W}$ & 0.05 hour & $0.001 \mathrm{kWh}$ & - \\
Weather station & $0.05 \mathrm{~W}$ & 24 hours & $0.00012 \mathrm{kWh}$ & - \\
IP camera & $10 \mathrm{~W}$ & 24 hours & $0.24 \mathrm{kWh}$ & - \\
Smart switches & $12 \mathrm{~W}$ & 24 hours & $0.288 \mathrm{kWh}$ & - \\
$4 \mathrm{G}$ wireless internet & $5 \mathrm{~W}$ & 24 hours & $0.12 \mathrm{kWh}$ & - \\
\hline Balance & $\approx$ & $0.76 \mathrm{kWh}$ & $1.23912 \mathrm{kWh}$ & $2 \mathrm{kWh}$ \\
\hline
\end{tabular}

Table 3. Construction material consumption for CIES

\begin{tabular}{|c|c|c|c|c|c|c|c|c|}
\hline Materials & $\begin{array}{c}\text { PVC } \\
\text { kg } \\
\end{array}$ & $\begin{array}{l}\mathbf{P P} \\
\mathrm{kg}\end{array}$ & $\begin{array}{l}\text { PE } \\
\text { kg }\end{array}$ & $\begin{array}{c}\text { Aluminum } \\
\text { Alloy } \\
\text { kg }\end{array}$ & $\begin{array}{c}\text { Stainless } \\
\text { Steel } \\
\text { kg }\end{array}$ & Ceramic & $\begin{array}{c}\text { Iron } \\
\mathrm{kg}\end{array}$ & $\begin{array}{c}\text { Cement } \\
t\end{array}$ \\
\hline $\begin{array}{l}\text { Rainfall } \\
\text { collection }\end{array}$ & 5 & 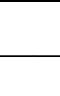 & 38 & 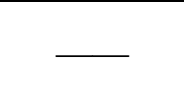 & - & - & - & - \\
\hline $\begin{array}{l}\text { Sewage } \\
\text { dealing }\end{array}$ & 5 & & 27 & - & - & - & 1 & - \\
\hline
\end{tabular}




\begin{tabular}{cccccccccc}
\hline $\begin{array}{c}\text { Hydroponic } \\
\text { farming }\end{array}$ & 395 & 43 & 17 & - & 2 & $120 \mathrm{~kg}$ & 19 & 8.5 \\
$\begin{array}{c}\text { Ceramic } \\
\text { facade }\end{array}$ & - & - & - & 130 & - & $3.36 \mathrm{t}$ & 295 & - \\
$\begin{array}{c}\text { Smart } \\
\text { equipment }\end{array}$ & - & 4 & - & 1.5 & - & - & 0.5 & - \\
\hline Total & 405 & 47 & 82 & 131.5 & 2 & $3.42 \mathrm{t}$ & 315.5 & 8.5 \\
\hline
\end{tabular}

PS: Black light lamp and solar power system were not included.

Table 4 . Water quality monitoring

\begin{tabular}{ccccccc}
\hline Testing & Underground & Rainfall & Hydroponic & Irrigation & $\begin{array}{c}\text { National } \\
\text { Irrigation }\end{array}$ & $\begin{array}{c}\text { National } \\
\text { Living }\end{array}$ \\
( mg/L $)$ & Water & Collection & Irrigation & Recycling & Standard & Standard \\
\hline $\mathrm{pH}$ & 7.6 & 8 & 8 & 8 & $5.5-8.5$ & $6.5-9$ \\
$\mathrm{BOD}_{5}$ & $<2$ & 6 & $<2$ & 20 & 40 & 10 \\
$\mathrm{COD}_{\mathrm{Cr}}$ & $<5$ & 10 & $<5$ & 44 & 100 & 50 \\
$\mathrm{SS}$ & 12 & 10 & 14 & 40 & 60 & 10 \\
$\mathrm{Cl}$ & 6.86 & 11.8 & 9.59 & 8.87 & 350 & 350 \\
$\mathrm{LAS}$ & $<0.05$ & $<0.05$ & $<0.05$ & $<0.05$ & 0.5 & 1 \\
$\mathrm{Cr}^{6+}$ & $<0.004$ & $<0.004$ & $<0.004$ & $<0.004$ & 0.1 & - \\
$\mathrm{TSC}$ & 171 & 195 & 180 & 152 & 1000 & - \\
$\mathrm{S}_{\mathrm{X}}$ & $<0.005$ & $<0.005$ & $<0.005$ & $<0.005$ & 1 & - \\
$\mathrm{Hg}$ & $<0.0001$ & $<0.0001$ & $<0.0001$ & $<0.0001$ & 0.001 & - \\
$\mathrm{As}$ & $<0.005$ & 0.038 & 0.043 & 0.01 & 0.05 & - \\
$\mathrm{Cd}$ & $<0.0001$ & $<0.0001$ & $<0.0001$ & $<0.0001$ & 0.01 & - \\
\hline
\end{tabular}

Table 5. Time consumption for a growing period for vegetables in the CIES

\begin{tabular}{ccc}
\hline Work & CIES Pattern & Traditional Pattern \\
\hline Seeding & 8 hours & 16 hours \\
Transfer sprouts & 8 hours & - \\
Daily management & $0.1 * 30=3$ hours & $1 * 30=30$ hours \\
Harvest & 4 hours & 16 hours \\
Cleaning and preparing & 2 hours & 4 hours \\
\hline Total & 25 hours & 66 hours \\
\hline
\end{tabular}

PS: Data for 4000 lettuces in a one-month growing period. 


\subsection{Environmental benefits}

The monitoring data above revealed that, in one CIES in Baoting, the engineering improved the ecological service. For example: 1) green area increased by $75 \mathrm{~m}^{2}$, 2) green volume increased by $40 \mathrm{~m}^{3}$, 3) $2400 \mathrm{~kg}$ of vegetables was harvested, 4) $70.87 \mathrm{t}$ of fresh water was saved, 5) $13500 \mathrm{~L}$ of sewage was disposed of, 6) $277 \mathrm{kWh}$ of electric power was saved, 7) $7.5 \mathrm{~kg}$ of chemical fertilizer was saved, and 8) $450 \mathrm{~g}$ pesticide was saved.

The emergy analysis method would is the correct choice for a deeper consideration of vegetable harvesting, power production and sewage treatment, as well as to compare the CIES pattern and traditional pattern. Using the emergy transformation parameters from Table 6 for $2.4 \mathrm{t}$ of vegetables, $277 \mathrm{kWh}$ of electric power generation and $1.35 \mathrm{t}$ of sewage treatment for calculation, we obtain Table 7, which reveals that only $19.4 \%$ of the emergy cost occurred in the CIES pattern compared with the traditional pattern.

Table 6. Emergy transformation

\begin{tabular}{cccc}
\hline Item & Unit & $\begin{array}{c}\text { Emergy } \\
\text { Transformation }\end{array}$ & Reference \\
\hline Solar & J & 1 & (Odum 1996) \\
Wind & J & $1.47 * 10^{3}$ & (Campbell et al. 2009) \\
Rain & J & $3.10^{*} 10^{4}$ & (Odum 1996) \\
Underground water & J & $2.55^{*} 10^{5}$ & (Bastianoni et al. 2011) \\
Soil loss & J & $1.24 * 10^{5}$ & (Williams 2002) \\
Chemical fertilizer & g & $2.80 * 10^{9}$ & (Williams 2002) \\
Pesticide & g & $2.49 * 10^{10}$ & (Williams 2002) \\
Labor force & J & $1.07 * 10^{6}$ & (Lan 1993) \\
Organic fertilizer & g & $7.20 * 10^{10}$ & (Cavalett et al. 2006) \\
Hydro power & J & $2.69 * 10^{5}$ & (Odum 1996) \\
Sewage treatment & g & $1.12 * 10^{7}$ & (Bastianoni et al., 2011) \\
\hline
\end{tabular}

Table 7. Comparing CIES with the traditional pattern for emergy analysis

\begin{tabular}{cccc|c}
\hline Item & $\begin{array}{c}\text { Usual Vegetable } \\
\text { Planting }\end{array}$ & $\begin{array}{c}\text { Usual Sewage } \\
\text { Treatment }\end{array}$ & $\begin{array}{c}\text { Hydropower } \\
\text { Generation }\end{array}$ & CIES \\
\hline Solar & $5.22 * 10^{12}$ & - & - & $5.27 * 10^{12}$ \\
Wind & $1.59 * 10^{14}$ & - & - & $1.59 * 10^{14}$ \\
Rain & $2.88 * 10^{14}$ & - & - & $2.88 * 10^{14}$ \\
Underground water & $4.35 * 10^{12}$ & - & - & $2.15 * 10^{10}$ \\
Soil loss & $1.18 * 10^{13}$ & - & - & - \\
Chemical fertilizer & $1.23 * 10^{14}$ & - & - & $6.15 * 10^{13}$ \\
Pesticide & $9.46 * 10^{12}$ & - & - & $9.46^{*} 10^{11}$ \\
\hline
\end{tabular}




\begin{tabular}{cccc|c}
\hline Labor force & $1.24 * 10^{15}$ & - & - & $4.71 * 10^{14}$ \\
Organic fertilizer & $3.25 * 10^{15}$ & - & - & - \\
Hydropower & - & - & $7.45^{*} 10^{7}$ & - \\
Sewage treatment & - & $1.51 * 10^{8}$ & - & - \\
\hline Total & & $5.09 * 10^{15}$ & & $9.86^{*} 10^{14}$ \\
\hline
\end{tabular}

If we consider the difference from a carbon footprint point of view between the CIES pattern and traditional pattern in one growing period, we only need to compare the difference in those variable costs, which means the chemical fertilizer cost and pesticide cost. According to a previous research result, $1 \mathrm{t}$ of nitrogen fertilizer costs $11.85 \mathrm{t}$ of $\mathrm{CO}_{2 \mathrm{eq}}$ (West and Marland 2002), and $1 \mathrm{t}$ of pesticide costs $13.8 \mathrm{t}$ of $\mathrm{CO}_{2 \mathrm{eq}}$ (Zhang 2010), and we can calculate that there is a $526.9 \mathrm{~kg} / \mathrm{a} \mathrm{CO}_{2} \mathrm{eq}$ cost in a traditional pattern. However, this number for the CIES pattern is $261.3 \mathrm{~kg} / \mathrm{a} \mathrm{CO}{ }_{2}$ eq. CIES only costs $49.6 \%$ of the carbon footprint of the traditional pattern.

\subsection{Economic benefit}

There was also a significant loss in economy. Based on the above data, we can determine that CIES could: 1) reduce the cost of power by $142 \mathrm{RMB}(0.512 \mathrm{RMB} / \mathrm{kWh} * 277 \mathrm{kWh}) ; 2)$ save 492 labor hours, which means more than 12300 RMB from other jobs ( $25 \mathrm{RMB} /$ hour * 492 hours); 3) produce $38400 \mathrm{RMB}(2 \mathrm{RMB} / \mathrm{Kg} * 2400 \mathrm{Kg} * 80 \%$, considering $20 \%$ damage and waste) from selling vegetables.

According to the construction costs listed in Table 8, $50550 \mathrm{RMB}$ is needed for a one-time investment and 11500 RMB will be needed annually for upkeep. We can determine that it would only take 1.28 years to recover all of the cost according to the following formula:

$$
50550+X \times(4000+7500)=X \times(142+38400+12300), X \approx 1.28
$$

Table 8. The construction cost for the CIES (RMB)

\begin{tabular}{ccc}
\hline Item & Material Cost & Labor and Machine Cost \\
\hline Rainfall collection & 3200 & 200 \\
Recycling fish tank & 3350 & 600 \\
Wall greening & 2000 & 200 \\
Rooftop farming & 9000 & 2000 \\
Artificial wetland & 5250 & 2000 \\
Solar power generator & 8500 & - \\
Smart control system & 6250 & 6000 \\
Logistic fee & - & - \\
Other auxiliary materials & 2000 & 11000 \\
\hline Total ( 50550 ) & 39550 & -
\end{tabular}

PS: It will cost $4000 \mathrm{RMB}$ for the renewal of consumable parts and $7500 \mathrm{RMB}$ for labor cost for system and vegetable management.

\section{Discussion}

4.1 Potential benefit after an application throughout Hainan Island 
This CIES engineering exhibit was built in Baoting County, but it is appropriate for use throughout Hainan Province. There are 4.72 million people living in the rural areas of Hainan. We hypothesize that half of these people could build CIESs for themselves, and every 6 people could have one. There would be 390 thousand CIESs in Hainan, leading to an income of 13.42 billion RMB local famers. Each famer would make 2842.38 RMB in income every year. In addition, this technology could decrease energy consumption $1.6^{*} 10^{21}$ sej and reduce 103.6 thousand tons of $\mathrm{CO}_{2 \mathrm{eq}}$ emissions.

4.2 A cheaper cost without the solar power system

The solar power system costs $21.5 \%$ of the entire CIES cost, and residential rural areas usually have a power supply. In this way, the solar power system could be dispensable. Without the solar system, the payback time would decrease from 1.28 years to 1.07 years. In addition, the omission of the solar power system would cause a small increase in the carbon footprint $(0.002 \%)$ and emergy $(0.0015 \%)$ because the electric supply is only a small component compared with the whole system. As a comprehensive consideration, we suggest that a CIES without a solar power system may be more efficient as an economy-environment benefit.

\subsection{Applicability for different climate zones}

This demonstration project was built in Baoting County, Hainan Province, China, which is a tropical zone with an abundant light and rain supply. If we want to promote this CIES to other regions of China, even to the entire world, parts of this system, such as a new roof water planting sub-system for a sloping roof and a new artificial wetland sub-system for winters with low temperatures, need to be redesigned. The research team is still working on this to make CIES more applicable for different climate zones and more convenient for installation.

4.4 The environmental cost of a solar power system

The missing consideration of the environmental impact of a solar power system is reasonable because its weight percentage in the whole CIES is less than $2 \%$, which is too low to reach the standard of a Life Cycle Assessment demand. In addition, the aim of this article is to provide a preview of the CIES, both its scientific design and benefits. The authors are working on another article to provide a special and deeper quantitative analysis on the environmental impact of the CIES.

\section{Conclusions}

The CIES built at Baoting was a demonstration project for the undeveloped tropical rural area and an integration of existing technologies, such as photovoltaic power, rooftop planting, the three box septic tank, an artificial wetland and composting fermentation, among others. However, the integrated system created more functions and benefits than the simple combination of each single technology.

According to data monitoring and the above analysis, we can conclude that each CIES could increase green land by $75 \mathrm{~m}^{2}$, green volume by $40 \mathrm{~m}^{3}$ and vegetables by $2400 \mathrm{~kg}$ for each rural family. The CIES can return more than 38,000 RMB after 1.28 years of payback. In addition, compared with the traditional pattern in the local area, the CIES pattern costs only $19.4 \%$ of the emergy of the traditional pattern and $49.6 \%$ of its carbon footprint. Assuming that CIES is applied to half of the rural households in the Hainan Province, each farmer would receive an extra 2842 RMB each year, the emergy consumed by the system would be reduced by $1.6^{*} 10^{21}$ sej, and $\mathrm{CO}_{2}$ emissions would be reduced by $1.036 * 10^{5} \mathrm{t}$.

Because the Chinese central government has planned the development orientation of Hainan 
Province as an international tourism island, we thought CIES would be a suitable engineering project for development for the other low population density area of Hainan, where there is no municipal infrastructure in the rural area.

Finally, the authors will continue to improve the current version of CIES to make it suitable for use in other climate zones and affordable for more people. More economic-environmental analysis methods, such as LCA, will be conducted in this area. We welcome global researchers to travel to Baoting county, Hainan province, to observe CIES for themselves and to participate in this research.

\section{Acknowledgement}

This research was supported by China Postdoctoral Science Foundation (Grant No.: 2015M580139) and CPSF-CAS Joint Foundation for Excellent Postdoctoral Fellows.

\section{Reference}

Alvarez, S., A. Carballo-Penela, I. Mateo-Mantecon, and A. Rubio. 2016. Strengths-Weaknesses-Opportunities-Threats analysis of carbon footprint indicator and derived recommendations. Journal of Cleaner Production 121:238-247.

Bastianoni, S., F. Morandi, T. Flaminio, R. M. Pulselli, and E. B. P. Tiezzi. 2011. Emergy and emergy algebra explained by means of ingenuous set theory. Ecological Modelling 222:2903-2907.

Campbell, D. E., H.-F. Lu, G. A. Knox, and H. T. Odum. 2009. Maximizing empower on a human-dominated planet: The role of exotic Spartina. Ecological Engineering 35:463-486.

Cavalett, O., J. F. d. Queiroz, and E. Ortega. 2006. Emergy assessment of integrated production systems of grains, pig and fish in small farms in the South Brazil. Ecological Modelling 193:205-224

Chen, H., and M. Zhang. 2013. Occurrence and removal of antibiotic resistance genes in municipal wastewater and rural domestic sewage treatment systems in eastern China. Environment International 55:9-14. 
Gao, J., R. Wang, and J. Huang. 2015. Ecological engineering for traditional Chinese agriculture-A case study of Beitang. Ecological Engineering 76:7-13.

Holland, R. A., K. Scott, E. D. Hinton, M. C. Austen, J. Barrett, N. Beaumont, T. Blaber-Wegg, G. Brown, E. Carter-Silk, P. Cazenave, F. Eigenbrod, K. Hiscock, T. Hooper, A. Lovett, E. Papathanasopoulou, P. Smith, A. Thomas, R. Tickner, R. Torres, and G. Taylor. 2016. Bridging the gap between energy and the environment. Energy Policy 92:181-189.

Jiang, S., L. Shen, W. Lu, and L. Zhou. 2011. The Impact of Infrastructure investment to Coordinated Urban and Rural Development in China. Pages 46-50 in D. Sun, W. P. Sung, and R. Chen, editors. Frontiers of Green Building, Materials and Civil Engineering, Pts 1-8.

Lam, L., K. Kurisu, and K. Hanaki. 2015. Comparative environmental impacts of source-separation systems for domestic wastewater management in rural China. Journal of Cleaner Production 104:185-198.

Lan, O. 1993. Emergy synthesis of the ecological and economical systems of China and its sustainable development and ecology. China Science and Technology Press Beijing.

Li, L. W., J. Liu, Z. Zhang, and H. Xu. 2015. Late-life depression in Rural China: do village infrastructure and availability of community resources matter? International Journal of Geriatric Psychiatry 30:729-736.

Li, Z., H. Liu, and J. Liu. 2010. Imbalance Analysis of Rural Infrastructure Construction in China. SCIENTIA GEOGRAPHICA SINICA 30.

Liang, W., X. Guo, Y. Yang, M. Lu, and Z. Wen. 1998. A STUDY OF THE ENERGY 
ANALYSIS AND NUTR IENT BALANCEOF THE COURTYARD ECOSYSTEM I N NORTHERN CHINA. Journal of nature resources 13:56.

Liu, Y., L. Jiang, G. Zeng, Y. Guo, and X. Hu. 2014. Research progress on rural decentralizaed sewage treatment technology in China. Word SCI-TECH R\&D 36:343-348.

Lu, B. 2001. Study onFunction and Structuarl Divesrity of Tytical Rural Yard Ecosystem Shanghai environmental sciences 20:46-52.

Ma, L., and F. He. 2014a. PROGRESS IN COMBINED TREATMENT TECHNOLOGY OF RURAL DOMESTIC SEWAGE IN CHINA. PROGRESS IN COMBINED TREATMENT TECHNOLOGY OF RURAL DOMESTIC SEWAGE IN CHINA 40:1-10.

Ma, L., and F. He. 2014b. PROGRESS IN COMBINED TREATMENT TECHNOLOGY OF RURAL DOMESTIC SEWAGE IN CHINA. Technology of Water Treatment 40:1-5.

Odum. 1996. Environmental accounting: Energy and environmental decision making. John Wilely, New York.

Odum, H. T., and N. Peterson. 1996. Simulation and evaluation with energy systems blocks. Ecological Modelling 93:155-173.

Wei, Y.-L., L.-J. Bao, C.-C. Wu, Z.-C. He, and E. Y. Zeng. 2015. Assessing the effects of urbanization on the environment with soil legacy and current-use insecticides: A case study in the Pearl River Delta, China. Science of the Total Environment 514:409-417.

West, T. O., and G. Marland. 2002. A synthesis of carbon sequestration, carbon emissions, and net carbon flux in agriculture: comparing tillage practices in the United States. Agriculture, Ecosystems \& Environment 91:217-232.

Williams, B. 2002. A compendium of data for emergy computation issued in a series of folios, 
handbook of emergy evaluation. University of Florida.

Wu, X. F., G. Q. Chen, X. D. Wu, Q. Yang, A. Alsaedi, T. Hayat, and B. Ahmad. 2015. Renewability and sustainability of biogas system: Cosmic exergy based assessment for a case in China. Renewable \& Sustainable Energy Reviews 51:1509-1524.

Xie, M., Y. Wang, M. Fu, and D. Zhang. 2013. Pattern dynamics of thermal-environment effect during urbanization: A case study in Shenzhen City, China. Chinese Geographical Science 23:101-112.

Yu, X. 2014. Is environment 'a city thing' in China? Rural-urban differences in environmental attitudes. Journal of Environmental Psychology 38:39-48.

Yu, X., Y. Geng, P. Heck, and B. Xue. 2015. A Review of China's Rural Water Management. Sustainability 7:5773-5792.

Zhang, T., Y. Tan, X. Zhang, and Z. Li. 2016. A glazed transpired solar wall system for improving indoor environment of rural buildings in northeast China. Building and Environment 98:158-179.

Zhang, W. 2010. Innovation ideas for the reduction the emissions of chemical fertilizer industry. Agricultural Means of Production:22.

Zhou, M., X. L. Zhao, and L. Huang. 2016. The effects of urbanization on the environment pollution in China (2002-2012).in W. P. Sung and J. C. M. Kao, editors. 2016 International Conference on Electronic, Information and Computer Engineering.

Zhou, Z. 2012. Sustainable Development of The "Four-In-One" Model in Rural Areas of Northern China: a Village Case Study. Pages 4771-4775 in C. S. Zhang, editor. Materials Science and Information Technology, Pts 1-8. 